\title{
Post discharge growth assessment in preterm infants. Implications of adopting the WHO standards
}

\author{
Carlos A. Fustiñana, M.D., ${ }^{a}$ Diana Rodríguez, M.D., ${ }^{a}$ Gonzalo Mariani, M.D. ${ }^{a}$
}

\begin{abstract}
Introduction. The WHO standards have been used as a gold standard for growth assessment in preterm infants since 1986. The introduction of the WHO standards in Argentina could improve detection of sub-optimal growth.

Objective. To compare the proportion of growth retardation in terms of weight, body height and head circumference in preterm infants with a birth weight less than $1500 \mathrm{~g}$ (VLBW) assessed according to the WHO standards and the Sociedad Argentina de Pediatría (SAP) standards.

Population and methods. Cohort study in VLBW newborn infants. Measurements included were weight, heightand head circumferences measured at $40,53,66,79$ and 92 postmenstrual weeks $( \pm 1$ week). Sex was recorded as an independent outcome measure for both standards (WHO and SAP). Mean Z scores were analyzed for both standards using Student's test, and the difference of proportions was assessed using the $\mathrm{c} 2$ test (OR; 95\% CI).
\end{abstract}

Results. Two hundred and four infants were included. No differences were observed in anthropometric outcome measures at birth by sex. A greater growth was seen in terms of weight and height as per the SAP standards compared to the WHO standards, which was more marked in male infants than female infants, and which diminished around their first year of life.

Growth retardation in terms of height was observed in both males and females assessed with the WHO standards. No differences were observed in head circumference. A higher proportion of patients with a weight below 2 standard deviations at 3 months old was found as per the $\mathrm{WHO}(p<0.01$; OR: 0.36 ; $95 \%$ CI: 0.15 $0.78)$, but that was not the case with height and head circumference.

Conclusions. This study allows to suggest that changing the standards does not imply a significant modification in our follow-up practice over the first year of life of an infant. Key words: prematurity, postnatal growth, WHO standards, SAP standards.

http:/ /dx.doi.org/10.5546/aap.2014.eng.141

E-mail Address:

Carlos A. Fustiñana, M.D: carlos.fustinana@ hospitalitaliano.org.ar

Conflict of Interest: None.

Received: 6-13-2013 Accepted: 9-04-2013 assess postnatal growth in preterm newborn infants, especially those with a birth weight less than 1500 g. ${ }^{2}$ Many Argentine institutions rendered them practical and useful for preterm follow-up groups, they were recommended by the Committee of Fetal-Neonatal Studies of $\mathrm{SAP}^{3}$ and demonstrated, in subsequent studies, that intrauterine growth retardation and neonatal morbidity had harmful effects on postnatal growth ${ }^{4}$ up to one year old.

Since the publication of the standards to date, several changes have taken place in neonatal care strategies, such as using exogenous pulmonary surfactants, ventilation strategies (non-invasive ventilation and high frequency ventilation), and the implementation of bundles to improve nutrition and reduce hospital-acquired infections, all of which resulted in optimization of effectiveness, had an impact on morbidity and mortality, and modified viability limits. ${ }^{5}$ Said strategies also improved growth results in these patients, but they are still far from meeting the expected goals.

In April 2006, the World Health Organization (WHO) published new child growth standards to assess growth up to 5 years old. ${ }^{6}$ This resulted in the replacement of the National Center for Health Statistics (NCHS) reference, which was not accepted in many countries, including Argentina.

The criteria used for preparing the new standards showed that healthy infants, independently from their birth setting, will have similar growth patterns if they grow in a careful environment (smoke free), have periodic pediatric controls, receive immunizations as scheduled, and similar nutrition practices are 
followed (specific foods for their first six months of life). The WHO standards are prescriptive (describe how children should growth) as opposed to the descriptive standards normally used to check a patient's growth.

The standards proposed by the WHO were validated in Argentina in a 0 to 5 year-old population in the city of Rosario, ${ }^{7}$ and were therefore implemented in this country. This situation has made us wonder if their application on a risk population, such as very low birth weight (VLBW) preterm newborn infants, would imply a rise in the detection of sub-optimal growth up to the first year of adjusted age.

The objective of this study was to compare the proportion of postnatal growth retardation in terms of weight, height, and head circumference in preterm infants with a birth weight less than $1500 \mathrm{~g}$ varies when using the WHO standards instead of the SAP standards, used to this date, in the follow-up during their first year of life.

\section{PATIENTS AND METHODS}

This was a retrospective, cohort study with data obtained from an active follow-up database of preterm infants with a birth weight less than $1500 \mathrm{~g}$, completed in a prospective manner. Weight, height and head circumferences measures performed at 40 , $53,66,79$ and 92 weeks ( \pm 1 week) of postmenstrual age were included. Weight was measured with a beam scale rounding up or down to the nearest full $10 \mathrm{~g}$. Height and head circumference were recorded to the nearest full milliliter by one of the authors (DR) as per the recommendations made by the SAP's Growth and Development Committee. Sex was recorded as an independent outcome measure because both standards (WHO and SAP) divide population into male and female infants.

All patients who had at least three measurements on the corresponding dates were included. Children with intrauterine growth restriction or a severe morbidity were also included because it was considered that such conditions would not modify the results of the assessment. Patients with major malformations were excluded. Birth weight, gestational age, adjusted age at discharge, and weight, height and head circumference at discharge were recorded.

Mean deviations were estimated calculating the deviation from the $\mathrm{Z}$ score at 40,53, 66, 79 and 92 weeks ( \pm 1 week) of postmenstrual age for each of the studied standards (SAP and WHO). Deviations were assessed using Student's test. Differences in proportions of males and females below 2 standard deviations (SD) as per each standard (SAP and WHO) were compared using the $\chi^{2}$ test and odds ratios and 95\% confidence intervals (CI) were calculated. The sample size was estimated at 135 patients to find a difference between the WHO and the SAP standards of at least $10 \%$ of patients with a weight below $2 \mathrm{SD}$, an OR 0.2 for a power of 80 and a $95 \%$ CI.

\section{RESULTS}

During the 2007-2010 period, 271 infants with a birth weight less than $1500 \mathrm{~g}$ were included in the follow-up program. Of them, 58 did not meet the three required measurements on the corresponding date and 9 had major congenital malformations ( 5 with isolated heart disease and 4 with genetic or chromosomal syndromes). Two hundred and four infants met inclusion criteria and were analyzed in the study. Table 1 shows group characteristics divided by sex. No differences in birth weight or gestational age were observed. Anthropometric characteristics and the adjusted age at discharge were also similar.

Table 2 shows mean and standard deviation values of the three anthropometric outcome measures divided by sex and with the standard deviation compared to the mean values of the SAP and WHO charts. Both weight and height showed differences between growth assessed as per SAP standards compared to the WHO standards. Differences in weight were highest at weeks 53 and 66, with a sharper difference in male infants (Figure 1) than female infants, and diminished at 1 year of postmenstrual age. Height as per the WHO standards also showed retardation in both males and females, but it was

TABLE 1. Mean and standard deviation values at birth and at discharge from the study group and proportion of low birth weight by sex

\begin{tabular}{lcc}
\hline & \multicolumn{2}{c}{ Mean \pm SD } \\
\hline & $\begin{array}{c}\text { Male infants Femaleinfants } \\
\text { (101) }\end{array}$ & (103) \\
\hline Birth weight (g) & $1160 \pm 237$ & $1110 \pm 247$ \\
Gestational age (weeks) & $29.4 \pm 2.8$ & $29.2 \pm 2.7$ \\
Weight at discharge (g) & $2466.9 \pm 622$ & $2467.2 \pm 607$ \\
Height at discharge (cm) & $43.9 \pm 2.9$ & $43.8 \pm 4.3$ \\
HC at discharge (cm) & $33.4 \pm 2.5$ & $33.1 \pm 2$ \\
Adjusted age at discharge (weeks) & $38.3 \pm 4.6$ & $38.1 \pm 4.5$ \\
Low weight for GA n (\%) & $41(41)$ & $42(40)$ \\
\hline
\end{tabular}

HC: head circumference.

GA: gestational age. 
more marked in girls, extending from week 53 up to week 79 inclusive (Figure 2). No differences were observed in follow-up of head circumference values with any of the standards.

When analyzing the proportion of patients whose weight was below 2 SD (Table 3) according to both standards, at 3 months of adjusted age (53 weeks), the SAP standards found a lower proportion of patients whose weight was below 2 SD ( $p<0.01$; OR: 0.36 ; 95\% CI: 0.15-0.78). No statistically significant differences were observed in the analysis of height and head circumference.

\section{DISCUSSION}

Postnatal growth of VLBW newborn infants is modified by the presence of intrauterine growth retardation and by postnatal morbidities. Prenatal injuries imply an aggression during critical periods of development, with marked implications on epigenetic programming and a potential impact in adult life.

They may cause heart diseases, obesity and type 1 diabetes. These effects were initially described by Barker and then corroborated by multiple observational and experimental studies. ${ }^{8-10}$ Prematurity-related postnatal morbidity was also identified as having a strong association with postnatal growth retardation, although related to conditions such as bronchopulmonary dysplasia, sepsis and necrotizing enterocolitis. Prematurity has also been associated with a nutritional deficit during the immediate neonatal period and consequences on growth recanalization rate. ${ }^{11}$

The standards prepared by the WHO have been widely disseminated in our field and have been adopted by the SAP. Such change resulted in several publications that analyzed the differences with national standards, ${ }^{12-14}$ and showed that the

TABLE 2. Mean and standard deviation values of the three anthropometric outcome measures divided by sex, with $\mathrm{Z}$ scores compared to mean values of WHO and SAP charts

\begin{tabular}{|c|c|c|c|c|c|c|c|}
\hline & Adjusted age & Sex & $\mathbf{n}$ & Mean \pm SD & Z (SAP) & Z (WHO) & $\Delta \mathbf{Z}$ \\
\hline \multirow[t]{10}{*}{ Weight (g) } & \multirow[t]{2}{*}{40 weeks } & Female infants & 103 & $2888 \pm 495$ & -0.9 & -1.02 & 0.3 \\
\hline & & Male infants & 101 & $3026.1 \pm 532$ & -0.8 & -1.1 & -0.3 \\
\hline & \multirow[t]{2}{*}{53 weeks } & Female infants & 65 & $5171.1 \pm 697$ & -0.6 & -1.2 & -0.6 \\
\hline & & Male infants & 63 & $5550.6 \pm 922$ & -0.4 & -1.2 & -0.8 \\
\hline & \multirow[t]{2}{*}{66 weeks } & Female infants & 71 & $6634.6 \pm 942$ & -0.11 & -0.86 & -0.75 \\
\hline & & Male infants & 73 & $7336 \pm 1113$ & -0.44 & -0.8 & -0.36 \\
\hline & \multirow[t]{2}{*}{79 weeks } & Female infants & 51 & $7680.9 \pm 1511$ & -0.01 & -0.7 & -0.69 \\
\hline & & Male infants & 52 & $8356.1 \pm 1139$ & -0.01 & -0.6 & -0.59 \\
\hline & \multirow[t]{2}{*}{92 weeks } & Female infants & 94 & $8472.9 \pm 1160$ & -0.33 & -0.4 & -0.07 \\
\hline & & Male infants & 96 & $9250.8 \pm 1456$ & -0.76 & -0.6 & 0.16 \\
\hline \multirow{10}{*}{$\begin{array}{l}\text { Height } \\
\text { length }(\mathrm{cm})\end{array}$} & \multirow[t]{2}{*}{40 weeks } & Female infants & 96 & $46.1 \pm 2.6$ & -2.3 & -2.3 & 0 \\
\hline & & Male infants & 92 & $46.9 \pm 3.1$ & -2.17 & -2.1 & 0.07 \\
\hline & \multirow[t]{2}{*}{53 weeks } & Female infants & 60 & $56.6 \pm 2.8$ & -1.25 & -2.0 & -0.75 \\
\hline & & Male infants & 58 & $58.0 \pm 3.4$ & -2.1 & -1.9 & 0.3 \\
\hline & \multirow[t]{2}{*}{66 weeks } & Female infants & 70 & $62.7 \pm 3.8$ & -0.68 & -1.9 & -1.2 \\
\hline & & Male infants & 70 & $65.6 \pm 4.7$ & -0.41 & -0.8 & -0.39 \\
\hline & \multirow[t]{2}{*}{79 weeks } & Female infants & 50 & $68.1 \pm 3$ & -0.42 & -0.8 & -0.38 \\
\hline & & Male infants & 52 & $69.6 \pm 3.9$ & -0.48 & -1.1 & -0.62 \\
\hline & \multirow[t]{2}{*}{92 weeks } & Female infants & 83 & $71.7 \pm 3.3$ & -0.85 & -0.7 & 0.05 \\
\hline & & Male infants & 96 & $73.4 \pm 4.7$ & -0.63 & -0.9 & 0.37 \\
\hline \multirow{10}{*}{$\begin{array}{l}\text { Head } \\
\text { circumference }(\mathrm{cm})\end{array}$} & \multirow[t]{2}{*}{40 weeks } & Female infants & 91 & $34.6 \pm 1.7$ & 0 & 0.1 & 0.1 \\
\hline & & Male infants & 86 & $34.9 \pm 1.4$ & -0.36 & 0.1 & 0.46 \\
\hline & \multirow[t]{2}{*}{53 weeks } & Female infants & 61 & $39.6 \pm 1.8$ & -0.18 & 0.12 & 0.3 \\
\hline & & Male infants & 61 & $40.4 \pm 1.6$ & -0.15 & 0.02 & 0.17 \\
\hline & \multirow[t]{2}{*}{66 weeks } & Female infants & 68 & $42.3 \pm 2.6$ & -0.35 & 0.01 & 0.36 \\
\hline & & Male infants & 64 & $43,7 \pm 2.2$ & $-0,08$ & 0,1 & 0.18 \\
\hline & \multirow[t]{2}{*}{79 weeks } & Female infants & 50 & $44.4 \pm 1.6$ & -0.20 & 0.1 & 0.3 \\
\hline & & Male infants & 51 & $45.1 \pm 1.8$ & -0.40 & 0.02 & 0.42 \\
\hline & \multirow[t]{2}{*}{92 weeks } & Female infants & 72 & $44.9 \pm 1.8$ & -0.58 & 0.1 & 0.68 \\
\hline & & Male infants & 79 & $46 \pm 1.9$ & -0.72 & 0 & 0.72 \\
\hline
\end{tabular}


FIGURE 1. Longitudinal curves showing weigh standard deviation scores during the first year of life. Results are divided by male and female infants comparing the SAP and WHO standards

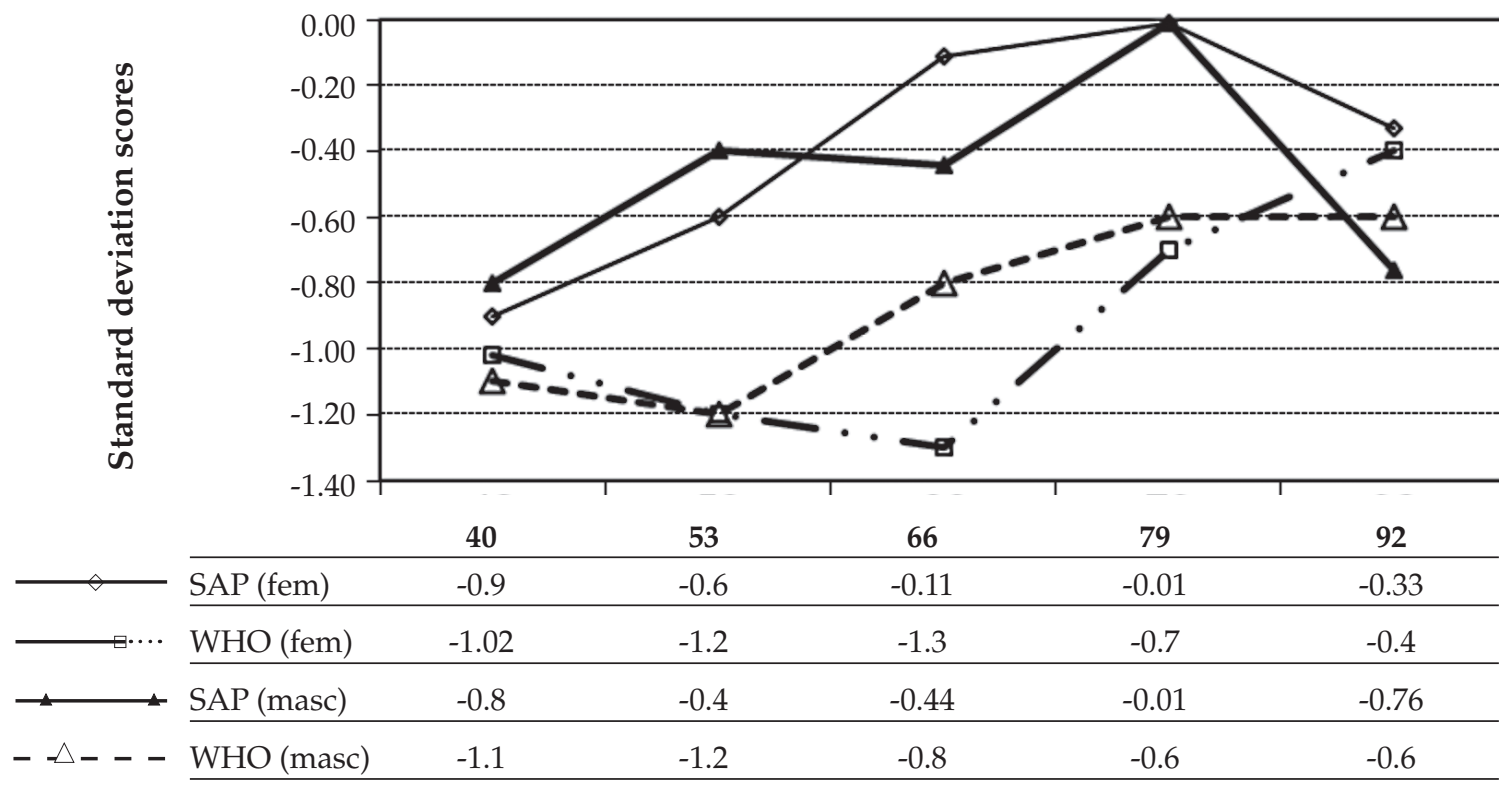

Postmenstrual age

FIGURE 2. Longitudinal curves showing height standard deviation scores during the first year of life. Results are divided by male and female infants comparing the SAP and WHO standards

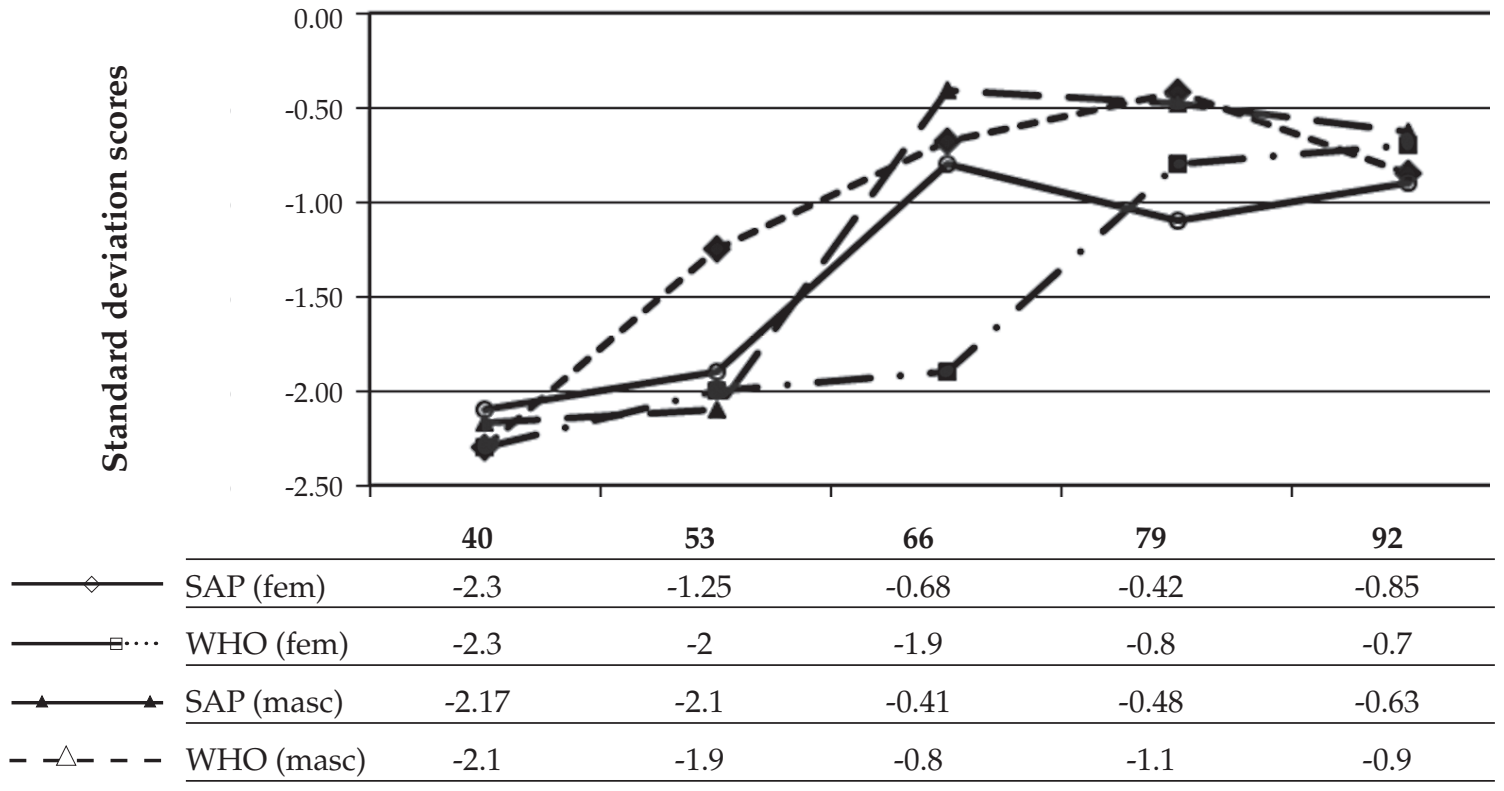

Postmenstrual age 
TABLE 3. Proportions ( $n, \%)$ of patients with weight and height values below 2 SD as per the SAP and WHO standards

\begin{tabular}{lcccccc}
\hline \multirow{2}{*}{$\begin{array}{l}\text { Adjusted age } \\
(\boldsymbol{n})\end{array}$} & Weight & \multicolumn{5}{c}{ Height } \\
\cline { 2 - 7 } & SAP $n(\%)$ & WHO $n(\%)$ & OR (IC 95\%) & SAP $n(\%)$ & WHO $n(\%)$ & OR (IC 95\%) \\
\hline 40 weeks (204) & $34(17)$ & $35(17)$ & $0.97(0.57-1.62)$ & $104(51)$ & $107(52)$ & $0.93(0.62-1.40)$ \\
53 weeks (188) & $35(18)$ & $40(21)$ & $0.84(0.51-1.40)$ & $9(4.8)$ & $23(12.3)$ & $0.36(0.16-0.80)^{*}$ \\
66 weeks (144) & $15(10)$ & $20(14)$ & $0.72(0.35-1.47)$ & $52(36)$ & $44(31)$ & $1.28(0.78-2.11)$ \\
79 weeks (102) & $11(11)$ & $9(9)$ & $1.93(0.69-5.44)$ & $19(19)$ & $20(19)$ & $0.94(0.47-1.87)$ \\
92 weeks (190) & $29(15)$ & $27(14)$ & $1.09(0.62-1.92)$ & $34(18)$ & $29(16)$ & $1.21(0.70-2.09)$ \\
\hline
\end{tabular}

international charts indicate a higher growth in terms of weight compared to the current standard. However, the fact that the study was prescriptive, characterized by healthy infants receiving pediatric follow-up, with complete immunization schedules and exclusively breastfed, represented a growth phenotype reference in adequate health conditions. ${ }^{15,16}$

In this context, we believed that it was advisable to assess the effect of adopting the WHO standards in a risk population such as VLBW newborns infants given that a higher proportion of infants with suboptimal postnatal growth identified due to a change in the standards may result in interventions considered unnecessary as per the current standards and increase the risk of overweight after one year of life.

Our analysis shows that at 3 months of adjusted age, the proportion of infants with sub-optimal weight was higher according to the WHO standards, and this finding is consistent with studies conducted before adopting the new standards. This effect could be attributed not only to prematurity but also to a low exclusive breastfeeding rate in this population and the lack of follow-on formulae for this population in our setting. No differences were observed in terms of height and head circumference; we believe this is mostly due to a lower discrepancy between the standards, especially in the case of head circumference charts, which are almost identical.

Nutritional intervention during the first year of life has proven to be effective to improve growth in terms of weight ${ }^{17}$ and height, independently of the intervention, as shown by the studies conducted by Lucas, ${ }^{18}$ who carried on a continued follow-up of a cohort of preterm infants fed with fortified formulae up to 9 months old and confirmed the modification of the caudate volume and performance at the initiation of adolescence in the group that received the higher energy density formula ${ }^{19}$.

Recent studies suggest that continuing with preterm formulae, which have a higher energy and protein density, could be beneficial for these infants. However, this information should be analyzed cautiously given that nutritional interventions in this period could have implications on the prevalence of obesity after one year of life. ${ }^{20,21}$ In addition, it should be acknowledged that the SAP standards we have used since the 70s did not regard obesity as a prevalent issue in this population. ${ }^{22}$

The WHO is focused on developing growth standards for preterm infants with prescriptive guidelines based on the discrepancies observed in growth assessments in this risk group, ${ }^{23,24}$ however, no data have been published to date. Although there are some reports available that show some results obtained with a similar project, ${ }^{25,26}$ we still have doubts regarding the feasibility of finding a "healthy" preterm population that could serve as control, especially if they were born before reaching 28 weeks of gestation.

Based on our study, we suggest that changing the standards to assess growth in the first year of life would not entail a significant modification in our follow-up practice from 40 weeks up to 1 year of adjusted age.

One of the strengths of this study is that the sample was made up of patients receiving a prospective follow-up by an observer trained in anthropometric measurements, therefore reducing inter-measurement variability. Also, appointment compliance enabled us to avoid using interpolations to assess growth at the indicated time points. One of the weaknesses of this study was that it is representative only of one institution and a multicenter study is required to make broader conclusions.

We believe that the use of the WHO standards could be improved and taken as a follow-up tool, including a scale ranging from 40 to 92 weeks correlated with the months of adjusted age for assessment so as to provide follow-up to preterm infants registered in follow-up programs. 


\section{Acknowledgments}

To Verónica Cravedi, M.D., for her participation in the early discussions about this study and who we will always remember with great fondness.

\section{REFERENCES}

1. Lejarraga H, Fustiñana C. Estándares de peso, longitud corporal y perímetro cefálico desde las 26 semanas hasta las 92 semanas de edad posmenstrual. Arch Argent Pediatr 1986;84:210-14.

2. Comité de Crecimiento y Desarrollo. Sociedad Argentina de Pediatría. Criterios de diagnóstico y tratamiento. Crecimiento y desarrollo. Buenos Aires: Sociedad Argentina de Pediatría; 1986.

3. Comité de Crecimiento y Desarrollo. Sociedad Argentina de Pediatría. Guías para la evaluación del crecimiento. $2^{\mathrm{a}}$ Ed. Buenos Aires: Sociedad Argentina de Pediatría; 2001.

4. Fustiñana C, Ceriani Cernadas J, Lejarraga H. Influencia del retardo del crecimiento intrauterino y de la morbilidad neonatal sobre el crecimiento y la morbilidad postalta en niños con muy bajo peso al nacer. Arch Argent Pediatr 1987;85:223-32.

5. Fustiñana CA, Izbizky G, Rodríguez D, Mariani G, Ceriani Cernadas JM. Evaluación de la efectividad de un programa de Cuidado Intensivo Neonatal en niños de muy bajo peso al nacer. Impacto de la administración de surfactante. Arch Argent Pediatr 2009;107(1):9-15.

6. WHO Multicenter Growth Reference Study Group. Assessment of differences in linear growth among populations in the WHO Multicenter Growth Reference Study. Acta Paediatr 2006; (Suppl 450):56-65.

7. Sguassero Y, Moyano C, Aronna A, et al. Validación clínica de los nuevos estándares de crecimiento de la OMS: análisis de los resultados antropométricos en niños de 0 a 5 años de la ciudad de Rosario, Argentina. Arch Argent Pediatr 2008;106(3):198-204.

8. Baker DPJ. Mothers, babies and health in later life. Edimburgo: Livingstone Ed.; 1998.

9. Gluckman PD, Cutfield W, Hofman P, Hanson MA. The fetal, neonatal, and environments the long-term consecuences for disease risk. Early Human Development 2005;81:51-9.

10. Bloomfield FH, Oliver MH, Hawkins P, Holloway AC, et al. Periconceptional undernutrition in sheep accelerates maturation of the fetal hypothalamic-pituitary-adrenal axis in late gestation. Endocrinology 2004;145:4278-85.

11. Embleton NE, Pang N, Cooke RJ. Postnatal malnutrition and growth retardation: an inevitable consequence of current recommendations in pre-term infants? Pediatrics 2001;107:270-3.
12. Lejarraga $\mathrm{H}$. Referencias y estándares de crecimiento en la Argentina. Consideraciones del Grupo ad hoc para el análisis de las tablas de la Organización Mundial de la Salud y su uso en la Argentina. Arch Argent Pediatr 2007;105(2):159-66.

13. Lejarraga H. Consideraciones sobre el uso de tablas de crecimiento en la Argentina: Arch Argent Pediatr 2007;105: $545-51$.

14. Comité de Crecimiento y Desarrollo. La Sociedad Argentina de Pediatría actualiza las curvas de crecimiento de niñas y niños menores de 5 años. Arch Argent Pediatr 2008;106(5):462-7.

15. Abeyá Gilardon E. La salud y las curvas de crecimiento. Arch Argent Pediatr 2007;106(1):92-3.

16. Abeyá Gilardon E. Curvas de crecimiento nacionales, ¿dónde estamos y hacia dónde vamos? Arch Argent Pediatr 2003;101(5):350.

17. Tyson JE, Lasky RE, Mize CE, Richards CJ, et al. Growth, metabolic response, and development in very-low-birthweight infants fed banked human milk or enriched formula. I. Neonatal findings. J Pediatr 1983;103:95-104.

18. Lucas A, Gore SM, Cole TJ, Bamford MF, et al. Multicentre trial on feeding low birthweight infants: effects of diet on early growth. Arch Dis Child 1984;59:722-30.

19. Isaacs EB, Gadian DG, Sabatini S, Chong WK, et al. The effect of early human diet on caudate volumes and IQ. Pediatr Res 2008;63(3):608-14.

20. Ong KK, Ahmed ML, Emmett PM, et al. Association between postnatal catch-up growth and obesity in childhood: prospective cohort study. BMJ 2000;320:967-71.

21. Ong KK. Catch-up growth in small for gestational age babies: good or bad? Curr Opin Endocrinol Diabetes Obes 2007;14:30-4.

22. Cusminsky M, Castro E, Azcona LCh, et al. Estudio longitudinal del crecimiento desarrollo del niño en La Plata. Comisión de Investigaciones, Científicas de la Provincia de Buenos Aires, La Plata; 1966.Págs.3-13.

23. de Onis M, Wijnhoven TMA, Onyango AW. Worldwide practices in child growth monitoring. J Pediatr 2004;144:461-5.

24. Villar J, Knight HE, de Onis M, Bertino E, et al; for the International Fetal and Newborn Growth Consortium (INTERGROWTH-21st). Conceptual issues related to the construction of prescriptive standards for the evaluation of postnatal growth of preterm infants. Arch Dis Child 2010;95(12):1034-8.

25. Bertino E, Gilli G, Occhi L, Giuliani F, et al. Postnatal growth of preterm infants: which reference charts? Minerva Pediatr 2010;62(3 Suppl 1):71-4.

26. Bertino E, Di Nicola P, Giuliani F, Coscia A, et al. Evaluation of postnatal growth of preterm infants. J Matern Fetal Neonatal Med 2011;24(Suppl 2):9-11. 